\title{
STRUCTURE AND MORPHOLOGY OF CELLULOSE FROM COCONUT COIR FIBERS
}

\author{
Pasang Patrik M. ${ }^{1,2 *}$, Yunianta ${ }^{3}$, Estiasih Teti $^{3}$, Harijono $^{3}$ \\ ${ }^{1}$ Graduate Program, Faculty of Agriculture, University of Brawijaya, Indonesia \\ ${ }^{2}$ Indonesian Palmae Research Institute, Manado, Indonesia \\ ${ }^{3}$ Faculty of Agricultural Technology, University of Brawijaya, Indonesia
}

*E-mail: patrikpasang@yahoo.com

\begin{abstract}
Coir fibers, which constitute the biggest part of coconuts, have not been used to the fullest. One way to increase the value added to the coconut fibers is by extracting the cellulose. Delignification and bleaching can be carried out simultaneously in the process of extracting the cellulose from coconut coir fibers. The purpose of this study was to determine the effects of delignification and bleaching carried out simultaneously on the structure and morphology of cellulose from coconut coir fibers. In the process, the powder of the coconut coir fibers was dissolved in ethanol $(1: 20 \mathrm{w} / \mathrm{v})$ with concentrations of ethanol of $30 \%, 40 \%$, and $50 \%$. Then, hydrogen peroxide and sodium hydroxide solution were added. The delignification and bleaching process was carried out at a temperature of $85^{\circ} \pm 2^{\circ} \mathrm{C}$, in respectively 90,120 , and 150 minutes. The spectrum analysis of the functional groups with Fourier Transform InfraRed (FT-IR) shows that the peaks for the functional groups of $\mathrm{O}-\mathrm{H}, \mathrm{C}-\mathrm{H},-\mathrm{CH}_{2}$ and 1,4- $\beta$ glycoside bonds as cellulose characteristics. The results of the analysis of the X-ray diffraction (XRD) indicate that the crystallinity index of the cellulose increased, and the XRD diffractogram major peaks at $2 \theta=22^{\circ}$. The morphological analysis with the scanning electron microscopy (SEM-EDX) shows that the treatment is quite effective to remove most of the silica bodies so as to improve accessibility for extracting the cellulose from the coconut coir fibers.
\end{abstract}

\section{KEY WORDS}

Coconut coir fibers, organosolv, cellulose, simultaneous process.

The coconut coir is the largest component of the coconut fruits, its availability is very abundant, but only a small fraction of it is used for industry. Most of the coconut coir becomes wasted in coconut plantations. One way to increase the added value of the coconut coir is by extracting the cellulose and then convert it into products that have economic values. The coconut coir is composed of fibers and powders, the main constituent of the coir fibers are the cellulose, hemicellulose, and lignin, with the proportion of $38.4 \%$ a-cellulose, 24.5\% hemicellulose, and 31.8\% lignin (Basu et al., 2015).

The cellulose polymers characterized as builders of the monosaccharide units. The glucose monomer units are bonded to one another to form a linear chain through the glycoside bonds which have a tendency to form intra and intermolecular hydrogen bonds. The $\mathrm{OH}$ groups of glucose units adjacent to the same cellulose molecules can form 'qa intramolecular hydrogen bonds. These bonds provide a certain rigidity in each chain. The $\mathrm{OH}$ group adjacent to the cellulose molecules can form intermolecular hydrogen bonds. These bonds lead to the formation of larger molecular structure. The hydrogen bond between the hydroxyl group at the adjacent chain cause a cellulose polymer that is relatively stable, insoluble in water and other solvents (Eichhorn et al., 2010). In nature, the cellulose chains are synthesized and formed into microfibrils consisting of crystalline and amorphous regions (Fernandes et al, 2011; Nishiyama, 2009), where the microfibrils form fibrils that will eventually become cellulose fibers. Based on its molecular structure, the cellulose can be dissolved in water because it contains many hydroxyl groups that can form hydrogen bonds with water. In fact, the cellulose is not only insoluble in water, but also in other solvents, the 
reason of which is the high rigidity of the chain and the chain intermolecular forces due to the hydrogen bonding between the hydroxyl groups of adjacent chains.

In lignocellulosic materials, cellulose is bonded together with hemicellulose and lignin by covalent bonding, various intermolecular bridges and van der Waals forces forming a complex structure (Kumar et al., 2010). The cellulose needs to be separated first from the hemicellulose and lignin before being used as the base material. The separation of the cellulose from the lignocellulosic materials can be done through delignification. Delignification aims to degrade and dissolve lignin optimally with minimal damage to the cellulose. Several studies have been investigated delignification the agricultural residues using different techniques (Gumuskaya et al., 2007; Law et al., 2007; Brigida et al., 2010; Bian et al., 2010; Johar et al., 2012; Penjumras et al., 2014; Arsyad et al., 2015) they were generally based on chemical treatments at the different route. Organosolv is delignification using an organic solvent to dissolve the lignin, the type of solvent used include ethanol, methanol, acetic and formic acid (Alaejos et al., 2006; Zhao et al., 2009; Vanderghem et al., 2012; Cybulska et al., 2015). The use of organic solvents intended to reduce the surface tension of the solution at a high temperature, accelerate the penetration into wood chips (Bendzala and Kokta, 1995). The delignification organosolv causes the loss of $\alpha$-aryl ether bond ( $\alpha-\mathrm{O}-4)$ and glycerol aryl$\beta$-aryl ether ( $\beta-O-4)$ contained in the lignin molecules (Sundquist, 1999), and then dissolving the lignin component in an organic solvent.

The organosolv process provides several advantages such as high-yield pulp produced, recycled black liquor can be done easily, the risk of contamination is low and easily recoverable (Caparros et al., 2007). The organosolv process that has been demonstrated in commercial alcell process that uses ethanol, acetocell process using acetic acid, and organocell process using methanol (Shatalov et al., 2005; Alaejos et al., 2006). Ethanol is preferred because of its ability to dissolve lignin, and its ease of recovery (Caparros et al., 2007; Wildschut et al., 2013), less expensive, and can be distilled from the black liquor for reuse as an extracting solution.

During this time, the process of delignification and bleaching is done separately. For the efficiency of the process, the delignification and bleaching can be performed simultaneously. The delignification and bleaching carried out simultaneously on the coconut coir fibers have never been done. In this study, ethanol was used in the delignification while in the bleaching is hydrogen peroxide was used as an ingredient. The purpose of this study was to determine the effects of delignification and bleaching carried out simultaneously on the structure and morphology of cellulose from coconut coir fibers. The functional groups of the cellulose were analyzed by Fourier Transform Infra-Red spectroscopy (FT-IR), the crystallinity index of the cellulose was analyzed by X-ray diffraction (XRD), the morphology of the cellulose was analyzed by a scanning electron microscopy (SEM-EDX).

\section{METHODS OF RESEARCH}

The coconut fibers were obtained from the experimental garden Kima Atas, Palmae Research Institute, Manado area, Indonesia. The other ingredients were ethanol, hydrogen peroxide $\left(\mathrm{H}_{2} \mathrm{O}_{2}\right)$, sodium hydroxide $(\mathrm{NaOH})$. The main equipment used included a hot plate, magnetic stirrer, three-neck flask, condenser, analytic balance, oven, and glass beaker.

Delignification and Bleaching. The coconut coir fibers and powder were separated from each other using a decorticator. Furthermore, the coconut fibers were destroyed using a grinder. The coconut fiber powder was sieved using a sieve sized 60 mesh. The process of delignification and bleaching was conducted simultaneously (modification of Tutus, 2004; Gumuskaya et al., 2007). Five grams of powder of the coconut coir fibers was dissolved in $100 \mathrm{ml}$ of ethanol, then $50 \mathrm{ml} \mathrm{H}_{2} \mathrm{O}_{2} 3 \%$ and $25 \mathrm{ml} \mathrm{NaOH} 1.5 \%$ were added. The proportion between the raw materials to the ethanol was $1: 20$, with concentrations of ethanol of $30 \%$, $40 \%$, and $50 \%$ and delignification times of 90,120 and 150 minutes. The process of delignification and bleaching was done in a high-neck flask equipped with a condenser, being stirre using a magnetic stirrer and a heat source coming from a hot plate at a temperature of $85^{\circ} \pm 2^{\circ} \mathrm{C}$. Once the process was complete, the sample was separated from the solution and 
washed with distilled water three times to remove the residual chemicals and then it was dried in an oven at a temperature of $60^{\circ} \pm 2^{\circ} \mathrm{C}$ for eight hours.

Characterization of Cellulose. The analysis of the functional groups of the cellulose samples was carried out by using an instrument-8400S Shimadzu FTIR spectrophotometer with $\mathrm{KBr}$ pellets (Rosa et al., 2010). The samples were characterized and added with $\mathrm{KBr}$, crushed, homogenized, and then placed in the sample holder, and irradiated with infrared rays. The spectrum of observations was maintained at a wavelength of $4000-400 \mathrm{~cm}^{-1}$ with a resolution of $16 \mathrm{~cm}^{-1}$.

The determination of crystallinity was done by using an instrument X-ray diffraction (XRD) PANalytical X'Pert MPD (Bian et al., 2012). The samples were placed in the sample holder with the X-ray source $\mathrm{Cu}(\lambda=0154 \mathrm{~nm})$, the generator voltage of $40 \mathrm{kV}$ and an electric current of $30 \mathrm{~mA}$ generator, the angle of diffraction $(2 \theta)$ used was $10-90^{\circ}$. In determining the crystallinity index, the following equation was used (Segal et al., 1959) :

$\mathrm{Crl}=\left[\left(\mathrm{I}_{002}-\mathrm{I}_{\mathrm{am}}\right) / \mathrm{I}_{002}\right] \times 100$

where $\mathrm{Crl}$ is the crystallinity index (expresses the relative degree of crystallinity), $\mathrm{I}_{002}$ is the maximum intensity of the 002 lattice diffraction $\left(I_{002}, 2 \theta=22^{\circ}\right), I_{a m}$ is the height of the minimum between the peaks of 002 and $101\left(\mathrm{I}_{\mathrm{am}}, 2 \theta=18^{\circ}\right) \cdot \mathrm{I}_{002}$ represents of the crystalline and amorphous regions, $I_{a m}$ represents of the amorphous regions.

The analysis of the surface morphology and elemental composition of the cellulose (Bian et al., 2012) was carried out by using a scanning electron microscopy instrument associated with energy dispersive X-ray (SEM-EDX Hitachi TM3000). The samples were placed in an aluminum plate that had two sides and then they were coated with gold and were subsequently observed at a voltage of $15 \mathrm{kV}$.

\section{RESULTS AND DISCUSSION}

FT-IR characterization. The FT-IR analysis is a method used to identify the presence of certain functional groups in the molecule, in which the functional groups generally have their own characteristics. This method is based on the interactions between the infrared radiation and matter, interactions in the forms of absorption at a particular wave number of energyrelated transitions between different energy states of vibration and rotation. The absorption peaks, which are observed with respect to the purity cellulose, are the wave number 1740 $\mathrm{cm}^{-1}, 1509 \mathrm{~cm}^{-1}$ and $1259 \mathrm{~cm}^{-1}$. The peak at $1740 \mathrm{~cm}^{-1}$ is related to the vibration acetyl group and ester uronat hemicellulose or chain esters of carboxylic group of ferulic acid and $\rho-$ kumarat lignin. A peak at $1509 \mathrm{~cm}^{-1}$ shows the $C=C$ vibration skeletal aromatic lignin. A peak at $1267 \mathrm{~cm}^{-1}$ is related to the strain CO hemicellulose and lignin (Rosa et al., 2010). The FTIR spectrum of cellulose from coconut coir fibers after the simultaneous process is presented in Figure 1 and the main absorption peaks are presented in table 1.

Based on Table 1, the observed wave number $\left(\mathrm{cm}^{-1}\right)$ of the cellulose of coconut coir fibers are seen at their peak with the wave number $3340-3394 \mathrm{~cm}^{-1}$ showing the stretching vibration of $\mathrm{OH}$ groups, the peak at $2898-2941 \mathrm{~cm}^{-1}$ showing the stretching vibration of the $\mathrm{CH}_{2}$ groups cellulose (Jahan et al., 2011; Rosa et al., 2012; Satyamurthy et al., 2011). The absorption peaks at wave number $1740 \mathrm{~cm}^{-1}$ were associated with stretching $\mathrm{C}=\mathrm{O}$ group and the acetyl ester uronat hemicellulose ester or carboxyl groups on the $\rho$-coumarat lignin (Alemdar and Sain, 2008). The loss of the peak at $1740 \mathrm{~cm}^{-1}$ shows that the delignification and bleaching conducted simultaneously could degrade hemicellulose and lignin, similar results were also reported by Alemdar and Sain, 2008; Nuruddin et al., 2011; Rosa et al., 2012. The peak that appears at wave number $1645-1649 \mathrm{~cm}^{-1}$ indicates infiltration of water and it is associated with bending vibration of water molecules due to the strong interactions between the cellulose and water (Johar et al., 2012; Rosa et al., 2012). The peak at wave number $1510 \mathrm{~cm}^{-1}$ shows the $\mathrm{C}=\mathrm{C}$ aromatic skeletal vibration of lignin, indicating that the removal of lignin has not been perfect. Sarkanen et.al (1967) used lignin spectrum to show that the absorption peak at wave number $1510 \mathrm{~cm}^{-1}$ contains lignin types guacyl. 

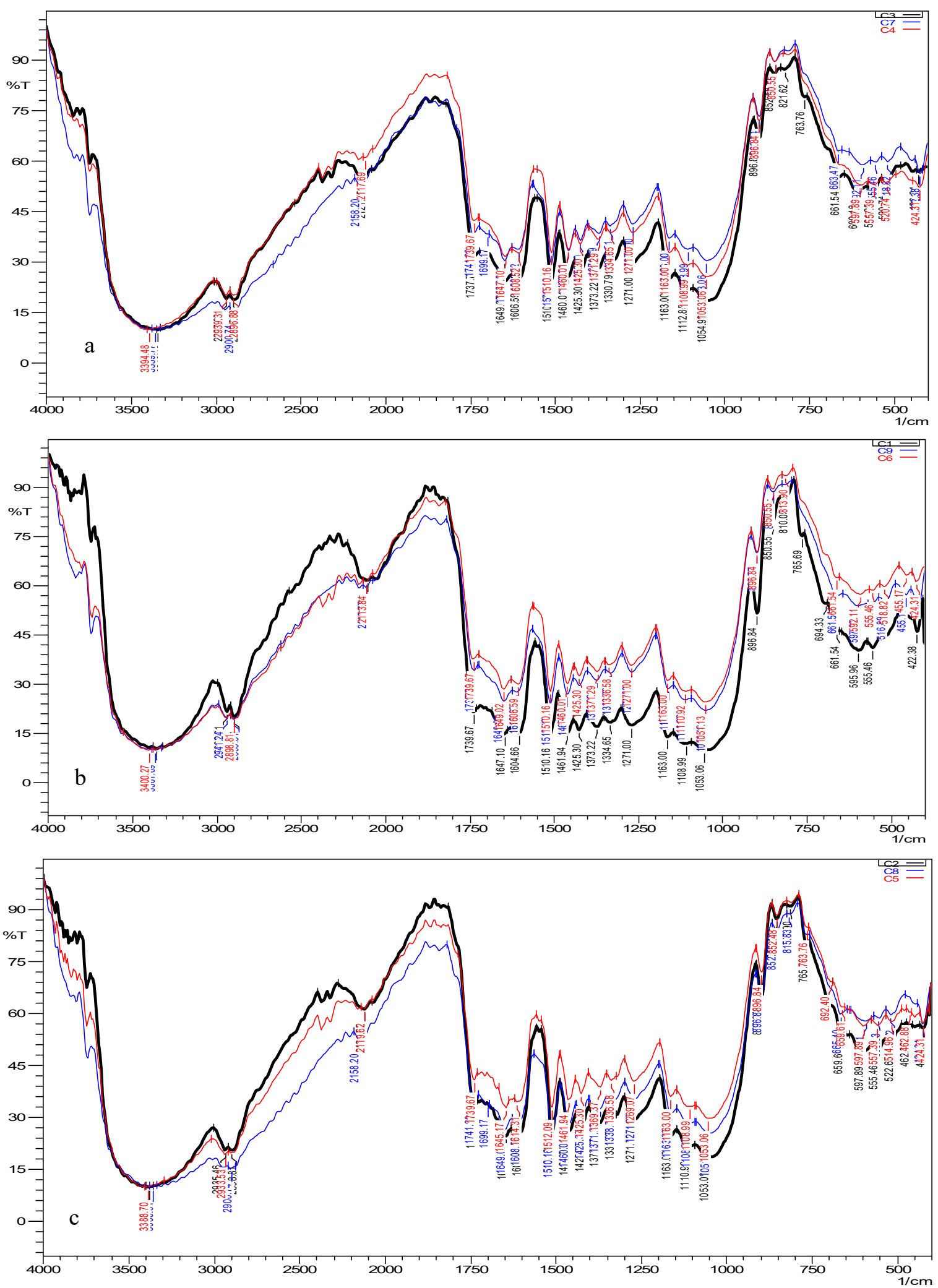

— ethanol 30\%— ethanol $40 \%$ — ethanol $50 \%$

Figure 1 - FTIR spectra of cellulose from coconut coir fibers with different concentrations ethanol treatments for 90 minutes (a); 120 minutes (b); and 150 minutes (c). The $x$-axis is the wave number $\left(\mathrm{cm}^{-1}\right)$, the $\mathrm{y}$-axis is the transmittance $(\%)$ 
The absorption peaks are important to help identify the cellulose component, which is $1420 \mathrm{~cm}^{-1}$, and are associated with the amorphous cellulose and crystalline cellulose II, while $1430 \mathrm{~cm}^{-1}$ is associated with the crystalline cellulose II (Wang et al., 2009). Generally, the symmetrical bending of $\mathrm{CH}_{2}$ amorphous cellulose and crystalline cellulose $\mathrm{I}$ is shown at wave number $1427 \mathrm{~cm}^{-1}$ (Bian et al., 2012). The $\mathrm{CH}_{2}$ symmetrical flexure in this study is detected at wave number $1425 \mathrm{~cm}^{-1}$, and according to Nelson and Connor (1964) it contains a mixture of the crystalline cellulose I and cellulose amorphous cellulose. Meanwhile, the emergence of the peak at $1373 \mathrm{~cm}^{-1}$ is associated with bending vibrations from the group $\mathrm{C}-\mathrm{H}$ and $\mathrm{C}-\mathrm{O}$ aromatic ring polysaccharide in the range of $1369-1373 \mathrm{~cm}^{-1}$ (Troedec et al., 2008). This is can be an indication of a larger exposition of the cellulose and hemicellulose on the fiber surface. The C-O stretching of aryl lignin can be observed with the advent of peak at 1235 $\mathrm{cm}^{-1}$ (Yang et al., 2007), but the results of this study indicate that the peak is not detected in the FT-IR spectrum. The peak which is not detected is probably caused by the degradation of the matrix structure of coconut coir fibers or restructuring some of the functional groups unstable into a more stable structure (Harun et al., 2013). The asymmetry stretching of C-O$C$ is shown at wave number $1163 \mathrm{~cm}^{-1}$. The vibration of $C_{1}-\mathrm{H}$ is a special vibe $C_{1}$ anomeric for $\beta$-glycoside, indicated by the appearance of the peak at wave number $896 \mathrm{~cm}^{-1}$ (Zhao et al., 2015).

Table 1 - Main absorption wave number $(\mathrm{cm}-1)$ of cellulose from coconut coir fibers

\begin{tabular}{lrrrrrrrrc}
\hline \multicolumn{1}{c}{ Functional group } & C1 & C2 & C3 & C4 & C5 & C6 & C7 & C8 & C9 \\
\hline O-H stretching & 3340 & 3359 & 3379 & 3394 & 3400 & 3388 & 3359 & 3361 & 3355 \\
H-C-H stretching & 2937 & 2939 & 2935 & 2939 & 2898 & 2933 & 2900 & 2941 & 2900 \\
O-H deformation $\mathrm{H}_{2} \mathrm{O}$ & 1649 & 1647 & 1645 & 1647 & 1649 & 1645 & 1649 & 1649 & 1649 \\
$\begin{array}{l}\text { C=C aromatic skeletal vibration of lignin } \\
\text { C-H deformation of cellulose }\end{array}$ & 1510 & 1510 & 1510 & 1510 & 1510 & 1512 & 1510 & 1510 & 1510 \\
$\begin{array}{l}\text { C-H, C-O aromatic vibration of } \\
\text { polysaccharide }\end{array}$ & 1425 & 1425 & 1425 & 1425 & 1425 & 1425 & 1425 & 1460 & 1425 \\
$\begin{array}{l}\text { C-O-C asymmetric stretching of cellulose, } \\
\text { hemicellulose }\end{array}$ & 1373 & 1373 & 1373 & 1371 & 1371 & 1369 & 1371 & 1373 & 1371 \\
glucose ring stretching (C) & 1163 & 1163 & 1163 & 1163 & 1163 & 1163 & 1163 & 1161 & 1163 \\
$\begin{array}{l}\text { C-O stretching of cellulose, hemicellulose, } \\
\text { lignin }\end{array}$ & 1112 & 1108 & 1110 & 1108 & 1110 & 1108 & 1108 & 1110 & 1108 \\
$\begin{array}{l}\text { Glucose ring stretching; C1-H deformation } \\
\text { of cellulose, hemicellulose }\end{array}$ & 1054 & 1053 & 1053 & 1053 & 1051 & 1053 & 1053 & 1051 & 1051 \\
\hline
\end{tabular}

C1 = ethanol 30\%,90 minutes; $C 2$ = ethanol 30\%,120 minutes; $C 3=$ ethanol 30\%,150 minutes;

C4 = ethanol 40\%,90 minutes; $C 5=$ ethanol 40\%,120 minutes; $C 6=$ ethanol 40\%,150 minutes;

$C 7=$ ethanol $50 \%, 90$ minutes; $C 8=$ ethanol 50\%,120 minutes; $C 9=$ ethanol $50 \%, 150$ minutes.

$X$-ray diffraction analysis. The cellulose consists of crystalline and amorphous regions which are randomly mixed. To analyze the crystal structure of the crystalline and amorphous regions, the X-ray diffraction is used as it allows to instantly capture images of the crystalline cellulose. The X-ray diffractogram of the crystalline region is indicated by a sharp peak while the amorphous is indicated by widened peaks. X-ray diffraction has been widely used to evaluate the crystalline structure of the cellulose since it provides a qualitative and semiquantitative evaluation of the amorphous and crystalline cellulosic components in a sample (Park et al., 2010). The crystallinity index of the cellulose is one of the important parameters of the crystal structure (Gharehkhani et al., 2015).

The crystallinity index of the cellulose can be improved by performing delignification and bleaching carried out simultaneously. The simultaneous process will hydrolyze the amorphous components remaining in the delignification process. The addition of $\mathrm{NaOH}$ causes the fiber surface to become more open and porous and that will facilitate penetration of hydronium ions to degrade the amorphous components thereby increasing the crystallinity of the cellulose (Khristova et al., 2012). The crystallinity index of cellulose from coconut coir fibers is presented in Table 2. 
Table 2 - The crystallinity index of cellulose from coconut coir fibers

\begin{tabular}{cc}
\hline Treatment & Crystallinity index $(\%)$ \\
\hline C1 & 51.58 \\
C2 & 44.59 \\
C3 4 & 52.12 \\
C5 & 54.05 \\
C6 & 48.71 \\
C7 & 48.96 \\
C8 & 52.09 \\
C9 & 49.76 \\
\hline
\end{tabular}

C1 = ethanol 30\%,90 minutes; $C 2$ = ethanol 30\%,120 minutes; $C 3=$ ethanol 30\%,150 minutes;

C4 = ethanol 40\%,90 minutes; C5 = ethanol 40\%,120 minutes; C6 = ethanol 40\%,150 minutes;

$C 7=$ ethanol 50\%,90 minutes; $C 8=$ ethanol 50\%,120 minutes; $C 9=$ ethanol 50\%,150 minutes.

The crystallinity index of coconut coir fibers is $47.30 \%$ before the treatment. After treatment, the crystallinity index is about 48.43 to $54.05 \%$. Crystallinity is low on raw coconut coir fibers because these crystalline regions are embedded in an amorphous component matrix such as hemicellulose, lignin. The changes in the crystallinity index can be attributed to the rearrangement of the cellulose molecules after removal of the amorphous components (Chen et al., 2011) because the amorphous regions easily absorb chemicals and undergo hydrolysis. The elimination of the amorphous components contributed to the increase in the crystallinity index so that the fibers will decrease swelling (Wan et al., 2011). $\mathrm{H}_{2} \mathrm{O}_{2}$ bleaching process effective in the elimination of the remaining amorphous constituents and thus increasing the crystallinity index. Delignification and bleaching carried out simultaneously were quite effective for increasing the hydrolyzing reagents to the cellulose content and reducing the amorphous content in the crystals. Amorphous components, in this case, hemicellulose and lignin have been partially reduced.

The treatment using a concentration of ethanol of $40 \%$ and delignification time of 90 minutes (C4) produces cellulose with the highest crystallinity index that is $54.05 \%$. The treatment using a concentration of ethanol of $30 \%$ and delignification time of 120 minutes (C2) produces cellulose with a crystallinity index lower than the raw material. This is because the swelling occurs only in the crystal so that the crystalline and amorphous persist (Jonoobi et al., 2011). The increased timing on the treatment processes of $\mathrm{C} 6$ and $\mathrm{C} 9$ causes a crystallinity index to be low because of the damage occurrence in the amorphous and the crystalline portion of a cellulose (Rosa et al., 2010). The XRD patterns of cellulose from coconut coir fibers are presented in Figure 2. The cellulose diffractogram in the coconut coir fibers shows that crystalline peaks are at $2 \theta=15^{\circ}$ and $2 \theta=22^{\circ}$ are the crystalline structure of the cellulose I (Nishiyama, 2009). The main peak of the cellulose in the coconut coir fibers diffractogram is shown in 002 peak $\left(2 \theta=22^{\circ}\right)$, indicating the removal of non-crystalline. Similar results were also reported by Fahma et al., 2011; Basu et al., 2015; Arsyad et al., 2015.

Morphological analysis. The analysis of the morphology of the raw material of coconut coir fibers and the cellulose extracted from the coconut coir fibers was carried out by using the SEM-EDX. The results of the analysis of the Scanning Electron Microscopy (SEM) can provide information on the shape and change the surface of a material being tested. The samples to be analyzed by the SEM should have a surface that is as reflective of electrons, so that the polymer material can be coated with gold in order to produce a sharp image of the surface. The Energy Dispersive X-Ray (EDX) one device used together with the SEM, EDX measurement which constitutes a quantitative analysis to determine the levels of elements in the samples of mass and atomic in percentages. Based on the analysis of the EDX in Table 3 , it is indicated that the content of the main elements of the coconut coir fibers is $\mathrm{C}, \mathrm{O}, \mathrm{Si}$ and K. Silica is a secondary macro elements that constitutes the core substance of plant protein to strengthen the walls of the cellulose. The potassium element plays an important role in the stomata, enzyme activities and promotes increased strengths and durability against the weathering and deformation of the cellulose. 

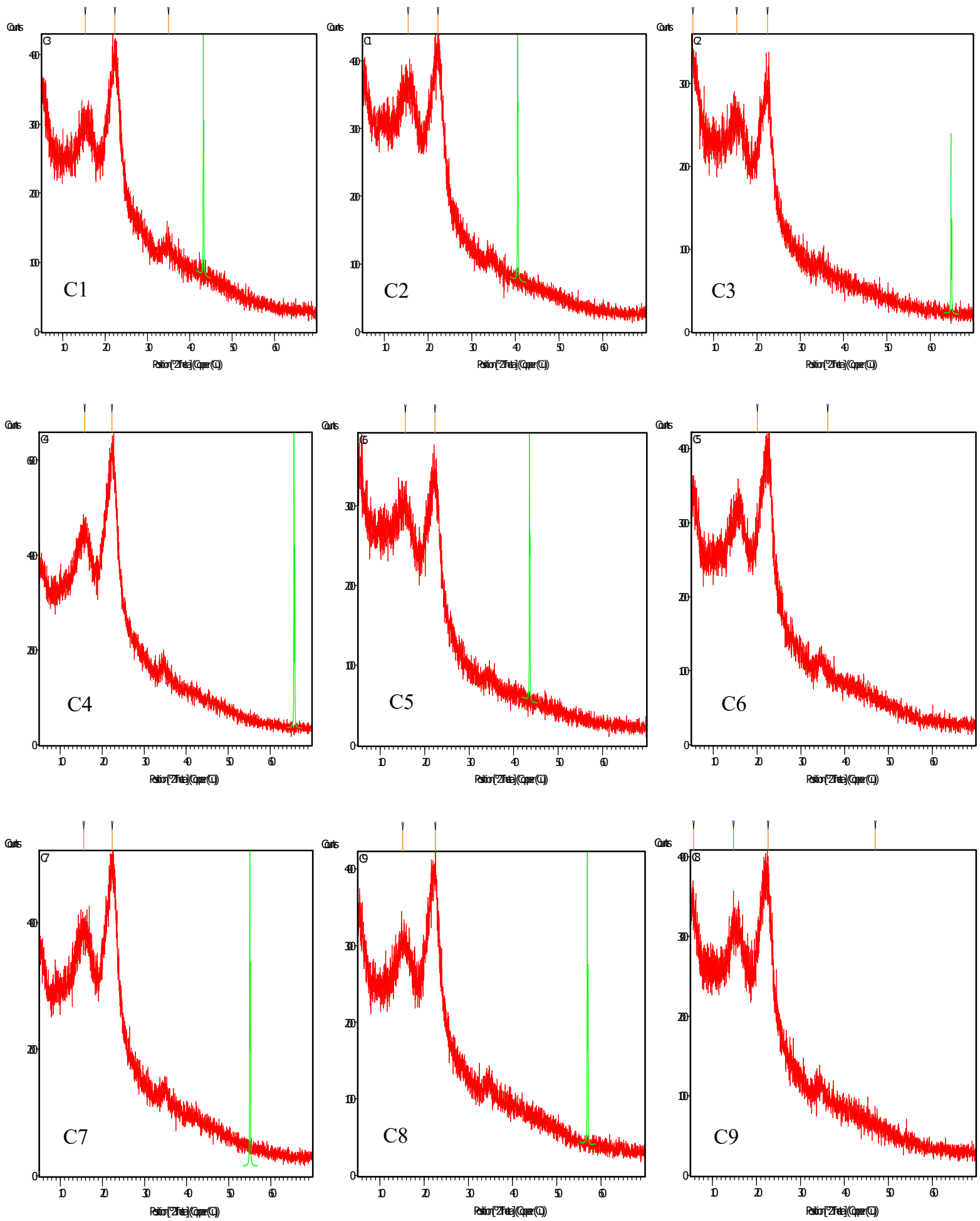

Figure $2-X R D$ patterns of cellulose from the coconut coir fibers at the various treatment. The $x$-axis is the angle of diffraction, 2 theta $\left({ }^{\circ}\right)$, the $y$-axis is the intensity count

Table 3 - The content of coconut coir fibers element before the treatments process based on the EDX analysis

\begin{tabular}{ccc}
\hline Element & Mass (\%) & Atomic (\%) \\
\hline $\mathrm{C}$ & 35.118 & 45.311 \\
$\mathrm{O}$ & 45.451 & 44.026 \\
$\mathrm{Si}$ & 19.053 & 10.513 \\
$\mathrm{~K}$ & 0.378 & 0.150 \\
\hline
\end{tabular}


The silica bodies become detached during the delignification and bleaching process carried out simultaneously leaving holes on the surface of the fiber. If observed carefully at the inside of the holes indicating the lines that connect the inside of silica to the surface of the fiber (Law et al., 2007). The loss of the silica bodies will increase the penetration of the chemical into the raw materials during the treatments. The shape, size and distribution patterns which are observed in the silica bodies of coconut coir fibers have similarities with empty bunches of oil palm fibers studied by Law et al., 2007. The silica bodies are pointy shaped and serve as a protection of the cellulose and give support to the plant structure. (Law et al., 2007; Neethirajan et al., 2009).

Before the treatments, it is shown the silica bodies spread over the surface of coconut coir fibers and other impurities (Figure 3a), the silica bodies are difficult to be degraded. The micrograph of the SEM of coconut coir fibers before and after the treatments is presented in Figure 3. After delignification and bleaching carried out simultaneously, it is shown that the structure of the fiber surface becomes smoother and cleaner. The treatment is effective enough to remove most of the silica bodies and waxy. On the surface of the fibers, holes are visible (Figure 3c). The released silica bodies can improve accessibility for extracting the cellulose from the coconut coir fibers. The EDX analysis results in Table 4, show that the main elements of the cellulose extracted from the coconut coir fibers are $\mathrm{C}$ and $\mathrm{O}$, while the Si element is not detected.

Table 4 - The element of the cellulose after delignification and bleaching carried out simultaneously processes

\begin{tabular}{cccccccccc}
\hline \multirow{2}{*}{ Element } & \multicolumn{10}{c}{ Atomic (\%) } \\
\cline { 2 - 10 } & C1 & C2 & C3 & C4 & C5 & C6 & C7 & C8 & C9 \\
\hline C & 64.301 & 74.778 & 80.815 & 60.420 & 71.949 & 66.529 & 64.702 & 60.892 & 88.734 \\
O & 35.699 & 25.222 & 19.185 & 38.727 & 28.051 & 33.471 & 35.298 & 38.806 & 11.266 \\
\hline
\end{tabular}

$C 1=$ ethanol $30 \%, 90$ minutes; $C 2=$ ethanol 30\%,120 minutes; $C 3=$ ethanol 30\%,150 minutes; C4 = ethanol 40\%,90 minutes; C5 = ethanol 40\%,120 minutes; C6 = ethanol 40\%,150 minutes; C7 = ethanol 50\%,90 minutes; $C 8=$ ethanol 50\%,120 minutes; $C 9=$ ethanol 50\%,150 minutes.
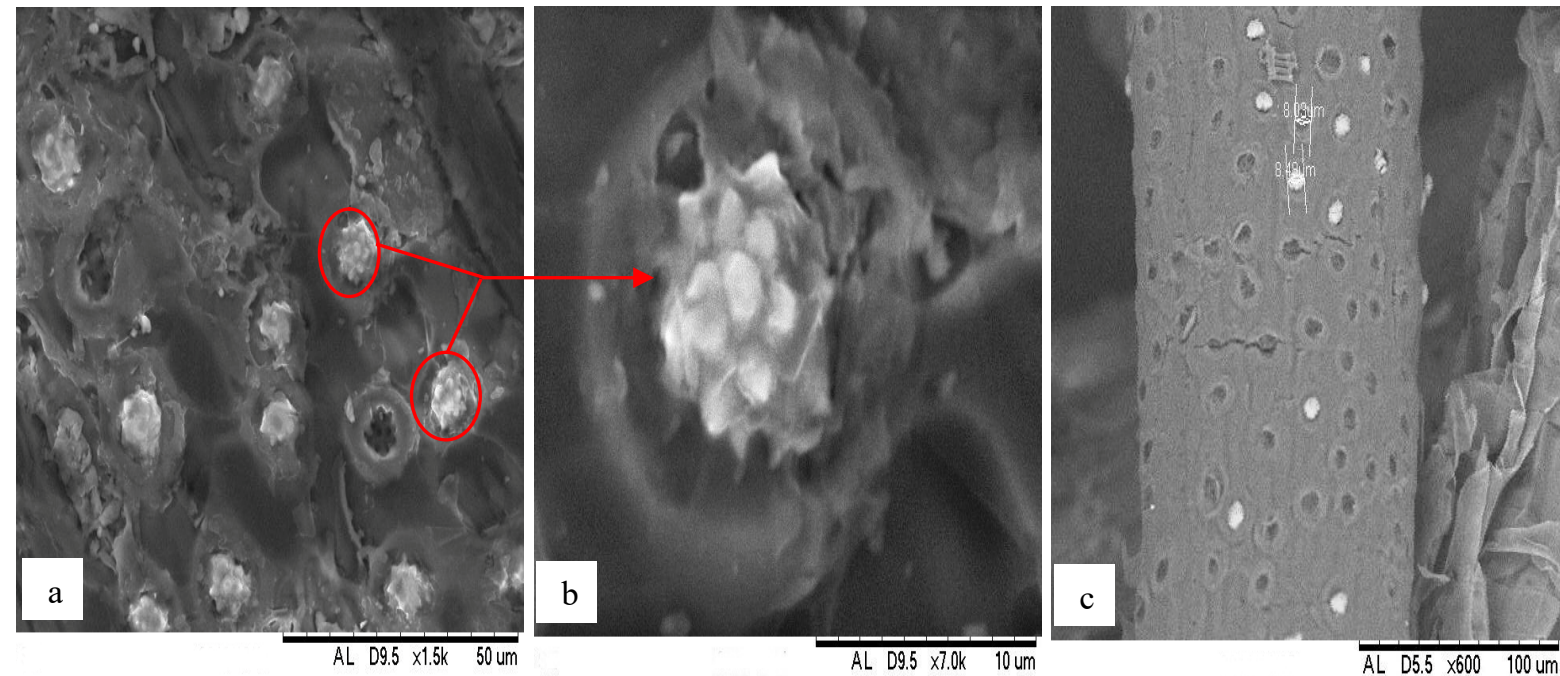

Figure 3 - SEM image of coconut fibers before the treatment with a magnification of $1500 x(a)$; the body of silica with a magnification of $7000 x(b)$, the cellulose of the coconut coir fibers after treatment with a magnification of $600 x(c)$

\section{CONCLUSION}

Cellulose in coconut coir fibers was successfully extraction through a treatment of delignification and bleaching carried out simultaneously. The FT-IR spectra show peaks for functional groups $\mathrm{O}-\mathrm{H}, \mathrm{C}-\mathrm{H},-\mathrm{CH}_{2}$ and 1,4- $\beta$ glycoside bond as cellulose characteristics. The 
crystallinity index of the cellulose increases after delignification and bleaching are conducted simultaneously. The highest crystallinity index of $54.05 \%$ was obtained from the treatment by using a concentration of ethanol of $40 \%$ and delignification time of 90 minutes. The morphological analysis with the scanning electron microscopy (SEM-EDX) shows that the treatment is quite effective to remove most of the silica bodies so as to improve accessibility for extracting the cellulose from the coconut coir fibers.

\section{ACKNOWLEDGEMENTS}

The authors are grateful to the Agency for Agricultural Research and Development, Ministry of Agriculture of the Republic of Indonesia for the funding of this research.

\section{REFERENCES}

1. Alaejos, J., Lopez, F., Eugenio, M. E., Tapias, R., 2006. Soda-anthraquinone, kraft and organosolv pulping of holm oak trimmings. Bioresource Technol. 97:2110-2116.

2. Alemdar, A., Sain, M., 2008. Isolation and characterization of nanofibers from agricultural residues-wheat straw and soy hulls. Bioresource Technol. 99:1664-1671.

3. Arsyad M., Gede Wardana, I. N., Pratikto, Irawan, Y. S., 2015. The morphology of coconut fiber surface under chemical treatment. Revista Materia 20:169-177.

4. Basu, G., Mishraa, L., Josea, S., Samanta, A. K., 2015. Accelerated retting cum softening of coconut fibre. Industrial Crops and Products 77:66-73.

5. Bendzala, J., Kokta, B. V., 1995. Optimization and fundamentals of high-yield pulping with ethanol. Wood Sci. Technol. 29:467-479.

6. Bian, J., Peng, F., Peng, X. P., Peng, P., Xu, F., Sun, R.C., 2012. Acetic acid enhanced purification of crude cellulose from sugarcane bagasse: structural and morphological characterization. BioResources 7:4626-4639.

7. Brigida, A. I. S., Calado, V. M. A., Goncalves, L. R. B., Coelho, M. A. Z., 2010. Effect of chemical treatments on properties of green coconut fiber. Carbohydrate Polymers 79: 832-838.

8. Caparros, S., Ariza, J., Garrote, G., Lopez, F., Diaz, J., 2007. Optimization of Paulownia fortunei $\mathrm{L}$. autohydrolysis organosolv pulping as a source of xylooligomers and cellulose pulp. Ind. Eng. Chem. Res. 46:623-631.

9. Chen, W., Yu, H., Liu, Y., 2011. Preparation of millimeter-long cellulose I nanofibers with diameters of 30-80 nm from bamboo fibers. Carbohydrate Polymers 86:453-461.

10. Cybulska, I., Brudeckia, G., Schmidta, J. E., Tomsena, M. H., 2015. Organosolv fractionation of palm tree residues. Energy Procedia 75:742-747.

11. Eichhorn, S. J. et al, 2010. Review: current international research into cellulose nanofibres and nanocomposites. J. Mater. Sci. 45:1-33.

12. Fahma, F., Iwamoto, S., Hori, N., Iwata, T., Takemura, A., 2011. Effect of pre-acidhydrolysis treatment on morphology and properties of cellulose nanowhiskers from coconut husk. Cellulose 18:443-450.

13. Fernandes, A. N., Thomas, L. H., Altaner, C. M., Callow, P., Forsyth, V. T., Apperley, D. C. Kennedy, C. J., Jarvis, M. C., 2011. Nanostructure of cellulose microfibrils in spruce wood. Proceedings of the National Academy of Sciences of the United States of America 108:1195-1203.

14. Gharehkhani, S., Sadeghinezhad, E., Kazi, S. N., Yarmand, H., Badarudin, A., Safaei, M. R., Nashrul, M., Zubir, M., 2015. Basic effects of pulp refining on fiber properties-A review. Carbohydrate Polymers 115:785-803.

15. Gumuskaya, E., Usta, M., Balaban, M., 2007. Carbohydrate components and crystalline structure of organosolv hemp (Cannabis sativa L.) bast fiber pulp. Bioresource Technol. 98:491-497.

16. Harun, N. A. F., Baharuddin, A. S., Huzairi, M., Zainudin, M., Bahrin, E. K., Nazli Naim, M., Zakaria, R., 2013. Cellulase production from treated oil palm empty fruit bunch degradation by locally isolated Thermobifida fusca. BioResources 8:676-687. 
17. Jahan, M. S., Saeed, A., He, Z., Ni, Y., 2011. Jute as raw material for the preparation of microcrystalline cellulose. Cellulose 18:451-459.

18. Johar, N., Ahmad, I., Dufresne, A., 2012. Extraction preparation and characterization of cellulose fibres and nanocrystals from rice husk. Industrial Crops and Products 37:93-99.

19. Jonoobi, M., Khazaeian, A., Tahir, P. Md., Azry, S. S. Oksman, K., 2011. Characteristics of cellulose nanofibers isolated from rubberwood and empty fruit bunches of oil palm using chemo-mechanical process. Cellulose 18:1085-1095.

20. Khristova, P., Tomkinson, J., Jones, G. L., 2003. Multistage peroxide bleaching of french hemp. Industrial Crops Products. 18:101-110.

21. Kim, U. J., Eom, S. H., Wada, M., 2010. Thermal decomposition of native cellulose: influence on crystallite size. Polym. Degrad. Stab. 95:778-781.

22. Kumar, S., Gupta, R., Lee, Y. Y., Gupta, R. B., 2010. Cellulose pretreatment in subcritical water: effect of temperature on molecular structure and enzymatic reactivity. Bioresource Technol. 101:1337-1347.

23. Law, K. N., Daud, W. R. W., Ghazali, A., 2007. Morphological and chemical nature of fiber strands of oil palm empty-fruit-bunch (OPEFB). BioResources 2(3):351-362.

24. Neethirajan, S., Gordon, R., Wang, L., 2009. Potential of silica bodies (phytoliths) for nanotechnology. Trends Biotechnology. 27:461-467.

25. Nelson, M. L., O'Connor, R. T., 1964. Relation of certain infrared bands to cellulose crystallinity and crystal lattice type. Part II. A new infrared ratio for estimation of crystallinity in cellulose I and II. J. Appl. Polym. Sci. 8:1325-1341.

26. Nishiyama, Y., 2009. Structure and properties of the cellulose microfibril. J. Wood Science. 55:241-249.

27. Nuruddin, M., Chowdhury, A., Haque, S. A., Rahman, M., Farhad, S. F., Jahan, M. S., 2011. Extraction and characterization of cellulose microfibrils from agricultural wastes in an integrated biorefinery initiative. Cellulose Chemical and Technology 45:347-354.

28. Park, S., Baker, J. O., Himmel, M. E., Parilla, P. A., Johnson, D. K., 2010. Cellulose crystallinity index: measurement techniques and their impact on interpreting cellulase performance. Biotechnology for Biofuels 3:1-10.

29. Penjumras, P., Rahman, R. A. B., Talib, R. A., Abdan, K., 2014. Extraction and characterization of cellulose from durian rind. Agriculture and Agricultural Science Procedia 2:237-243.

30. Rosa, M. F., Medeiros, E. S., Malmonge, J. A., Gregorski, K. S., Wood, D. F., Mattoso, L. H., Glenn, G., Orts, W. J., Imam, S. H., 2010. Cellulose nanowhiskers from coconut husk fibers: Effect of preparation conditions on their thermal and morphological behaviour. Carbohydrate Polymers 81:83-92.

31. Rosa, S. M. L., Rehman, N., De Miranda, M. I. G., Nachtigall, S. M. B., Bica, C. L. D., 2012. Chlorine-free extraction of cellulose from rice husk and whisker isolation. Carbohydrate Polymers 87:1131-1138.

32. Satyamurthy, P., Jain, P., Balasubramanya, R. H., Vigneshwaran, N., 2011. Preparation and characterization of cellulose nanowhiskers from cotton fibres by controlled microbial hydrolysis. Carbohydrate Polymers 83:122-129.

33. Sarkanen, K.V., Chang, H. M., Erickson, B. 1967. Species variation in lignins. I. Infrared spectra of guaiacyl and syringyl models. Tappi J. 50: 572-575.

34. Segal, L., Creely, J. J., Martin, A. E., Conrad, C. M., 1959. An empirical method for estimating the degree of crystallinity of native cellulose using the X-ray diffractometer. Textile Research Journal 29:786-794.

35. Shatalov, A. A., Pereira, H., 2005. Arundo donax L. reed: new perspectives for pulping and bleaching. Part 4. Peroxide bleaching of organosolv pulps. Bioresource Technol. 96:865-872.

36. Sundquist, J., 1999. Organosolv pulping. Chemical pulping at paper making science and technology, Helsinky Finland.

37. Troedec, M., Sedan, D., Peyratout, C., Bonnet, J., Smith, A., Guinebretiere, R., Gloaguen, V., Krausz, P., 2008. Influence of various chemical treatments on the composition and structure of hemp fibers. Compos Part A 39:514-522. 
38. Tutus, A., 2004. Bleaching of rice straw pulps with hydrogen peroxide. Pakistan Journal of Biological Science 7:1327-1329.

39. Vanderghem, C., Brostaux, Y., Jacquet, N., Blecker, C., Paquot, M., 2012. Optimization of formic/acetic acid delignification of Miscanthus giganteus for enzymatic hydrolysis using response surface methodology. Industrial Crops and Products 35:280-286.

40. Wan, J., Yang, J., Ma, Y., Wang, Y., 2011. Effects of the pulp preparation and paper making processes on the properties of OCC fibers. BioResources, 6:1615-1630.

41. Wang, K., Jiang, J., Xu, F., Sun, R., 2009. Influence of steaming explosion time on the physic-chemical properties of cellulose from Lespedeza stalks (Lespedeza crytobotrya). Bioresource Technol. 100:5288-5294.

42. Wildschut, J., Smit, A. T., Reith, J. H., Huijgen, W. J. J., 2013. Ethanol-based organosolv fractionation of wheat straw for the production of lignin and enzymatically digestible cellulose. Bioresource Technol. 135:58-66.

43. Yang, H., Yan, R., Chen, H., Dong, H. L., Zheng, C., 2007. Characteristics of hemicellulose, cellulose and lignin pyrolysis. Fuel 86:1781-1788.

44. Zhao, X., Cheng, K., Liu, D., 2009. Organosolv pretreatment of lignocellulosic biomass for enzymatic hydrolysis. Applied Microbiology and Biotechnology 82:815-827.

45. Zhao, Y., Xua, C., Xing, C., Shia, X., Matuanab, L. M., Zhoua, H., Ma, X., 2015. Fabrication and characteristics of cellulose nanofibril films from coconut palm petiole prepared by different mechanical processing. Industrial Crops and Products 65:96-101. 